\title{
Conceptual framework for estimating postharvest losses in food supply chains: The case of plantain fruits in Nigeria
}

\author{
Kwami Justina Kenobi Morris, Nitty Hirawaty Kamarulzaman* \\ Department of Agribusiness and Information Systems, Universiti Putra Malaysia, 43400 UPM Serdang, Selangor, Malaysia
}

Email address:

nitty@upm.edu.my (N. H. Kamarulzaman)

\section{To cite this article:}

Kwami Justina Kenobi Morris, Nitty Hirawaty Kamarulzaman. Conceptual Framework for Estimating Postharvest Losses in Food Supply Chains: the Case of Plantain Fruits in Nigeria. International Journal of Business and Economics Research. Special Issue: Supply Chain Management: Its Theory and Applications. Vol. 3, No. 6-1, 2014, pp. 31-37. doi: 10.11648/j.ijber.s.2014030601.15

\begin{abstract}
Postharvest losses which refer to the measurable quantitative and qualitative food losses in any agro-food supply chain account for significant amounts of food loss. Lack of consistent information on exact amount of losses and assessment methods further complicate the problems and makes solutions very difficult. Plantain also known as cooking banana is an important staple food and cash crop in Nigeria with observed high postharvest losses. The current study proposes a conceptual framework for directly estimating postharvest losses and identifying causative factors using a commodity system approach.
\end{abstract}

Keywords: Postharvest, Losses, Food Supply Chain, Plantain, Nigeria, Causative Factors

\section{Introduction}

Food losses attain increased attention in recent times. It is predicted that about 1.3 billion tons of food is lost each year [28]. While a reasonable part of food losses results from food waste in developed countries, a major portion of food loss in developing countries is owing to high postharvest losses (PHLs) in food supply chains (FSC). PHLs which refer to the measurable quantitative and qualitative food losses in any postharvest system account for significant amounts of global food loss [21, 37, 43].

In Nigeria, where the agriculture sector contributes more than $30 \%$ of the GDP and employs about $70 \%$ of the labor force [39], high PHLs has continued to be observed in FSCs of perishable agricultural commodities such as fruits and vegetables $[31,40]$. Although inadequate infrastructure and socio-economic constraints are suggested to limit adoption of proven postharvest technologies that would have curbed losses; lack of uniform information on the extent of PHLs, major sources of PHLs and methods for assessment of PHLs further constrain the situation. [35] noted measurement as the logical first step towards mitigating PHLs. The current study therefore, seeks to evaluate the causative factors and extent of PHLs in plantain FSC in Nigeria.

Plantain also known as cooking banana is an important staple food and cash crop in tropical regions like Nigeria and West Africa at large [1, 7, 26, 32]. In 2012, worldwide production of plantain and banana were estimated to be approximately 102 million metric tons [47]. Seven out of the top ten worldwide plantain producing countries are from subSaharan Africa, where most of the commodity is consumed domestically or near production areas. Although banana has being exported more than plantain, its production far exceeds banana production in Africa where about 70 million people derive more than $25 \%$ of their carbohydrate requirement from plantains. Plantain production is thus a significant component to food security especially in West Africa which accounts for about 32\% (12.46 million metric tons) of global production in 2011 [18].

In Nigeria, plantain has export and economic development potentials as well as strengthening food security. Nevertheless, plantain fruits are highly perishable and the industry in Nigeria, is been limited by poor postharvest systems causing quality deterioration and finally high PHLs $[2,19,23]$. Geographically located in West Africa, Nigeria is ranked sixth position among world highest plantain producing countries according to statistics by the Food and Agricultural Organization (FAO). Owing to favorable production conditions (such as climatic factors, fertile forests, laterite soils) plantain production in Nigeria is concentrated only in the southern part of the country [7] with highest production regions located in the South-South states (Bayelsa, 
Rivers State, Akwa Ibom) and South-West (Oyo state). In 2012, plantain production in Nigeria was estimated to be 2.8 million tons and valued at USD1,850 million [25]. From production figures by the FAO in 2012 [25], plantain production in Nigeria has doubled in the last two decades, from 1.417 million tons in 1992 to 2.8 million tons in 2012. But still economic growth of the industry has been insignificant compared to other West African countries like Ghana which experienced a rapid industrial growth from insufficient production to a net exporter. In addition to this, domestic demands in plantain fruits are hardly met with exports still insignificant. This is partly owing to low yields as production fate is still in the hands of smallholder farmers in rural areas $[36,39]$ with mostly no access to extension services. Also contributing to the problem is the issues of poor harvest quality, wrong postharvest handling and storage practices have further worsened the situation [7].

Poor quality harvest and short shelf life coupled with lack of proper postharvest systems cause fast deterioration of product quality and economic value as produce moves down the supply chain. Looking at FSCs in Nigeria, while there are numerous studies in this respect, information on estimation methods and exact amount of PHLs for most commodities is conflicting, even for plantain. For instance, plantain postharvest losses (discarded volume) in the country were reported to be as high as $40 \%$ [41], whereas studies by [6] in the same year reported postharvest economic losses in banana and plantain fruits to be $17 \%$ in Southeastern and Southwestern Nigeria collectively. The same study noted only a $3 \%$ economic value losses for fruits traded in Southeastern Nigeria [6], thereby indicating that losses may vary for different regions in same country. Another studies on plantain/banana postharvest losses in Lagos metropolis market (located in the Southwest) showed losses of $6.62 \%$ per lorry trip during peak season and $2.5 \%$ per lorry trip during off season [3], whereas plantain postharvest losses as high as $27 \%$ were estimated in Rivers State (located in the South-South region of the country) [39]. [5] explained that variations in postharvest losses may be as a result of differences in postharvest technologies being practiced in the different production areas.

It is noteworthy that since plantain is consumed in almost all stages of ripeness for different culinary uses; conflicting figures of losses are worrisome and may or may not be as high as reported. On another note, it may imply that majority of the PHLs in plantain are rather reduction in fruit quality which is likely to be progressive as the commodity travels down the distribution chain. Another significant fact is; most of the documented studies on plantain PHLs in Nigeria focused only on a specific part of the supply chain, therefore PHLs figures may not be representative of the entire FSC and estimates were obtained by subjective estimates (surveys/interviews) not direct measurements. Subjective estimates may not be true representative figures of losses because there is the possibility of either overestimates or underestimation [43]. Again, this further emphasizes the poor state of postharvest management in the country and a high need to establish an accurate or near accurate PHLs estimation procedure for FSCs and as well document causes of losses.

Scarcity and urgent need for such vital and comprehensive information [30, 43] in postharvest management makes it imperative to establish frameworks for accurate estimation, quantification and documentation of PHLs and causes of losses. More so, identifying the extent to which each causative factor contributes to total PHLs in the entire the supply chain is important to consummately understand and identify workable solutions for a better functioning plantain postharvest system and FSC in the country.

\section{Plantain Prices and Consumption Trends}

In the recent decades, price per ton of plantain has increased steadily in most producing West African countries such as Cote d'Ivoire, Ghana, Cameroon, etc. Inflation in the 1990s which caused huge price increase of most agricultural commodities in Nigeria also spiked price per metric ton of plantains from about USD500 in the early 1990s to more than USD2000 in the late 1990s; this was followed by a corresponding drop in plantain prices to USD500 in 1999. And from then onwards plantain fruits prices have increased steadily over the years $[18,25,36]$.

Average annual consumption of plantain and banana by Africans is estimated at $21 \mathrm{~kg}$ per capita with Ugandans consumption averaged at about $121 \mathrm{~kg}$ per capita [33]. Despite increasing prices, plantain consumption in West Africa has doubled in the last two decades (from less than 6 million tons consumed in 1990 to more than 12 million tons in 2009). In 2009, $39 \mathrm{~kg}$ per capita was the average plantain consumption by West Africans [18]. High plantain consuming areas like southwest Cameroon and other regions averaged up to $150 \mathrm{~kg}$ of per capita consumption per year [18, 48]. In Nigeria, plantain is ranked third in consumption among starchy staples [7]. Although on a per capita consumption basis, Nigeria is the least as compared to other African countries [14]. A survey study on Nigerian women who were decision makers in household food purchase showed a high percentage of increasing their consumption of plantain if prices decreased [4]. Similarly, another survey study in Cameroon [22] where 355 housewives were asked which of the starch staples (plantain, cassava, rice, cocoyam, maize) they would prefer supposing prices were the same; showed that $55 \%$ of the respondents would choose plantain while $72 \%$ of respondents would include plantain among their top three favorite foods. The same study evaluated respondents from North Cameroon where plantain is expensive and not a staple. It was observed that most respondents would chose plantain as their first choice of food to purchase if they had more income [22]. The discussed consumption trends thus positively indicate higher market prospects for plantain production in Nigeria, both for consumption and export earnings. 


\section{Challenges of Plantain Postharvest System in Nigeria}

A postharvest system comprises all after harvest activities involved when an agricultural product moves along the FSC from farm to the point of consumption [30]. Considering postharvest as a system, [13] emphasized the importance of noting that producers, suppliers and other supply chain actors have a duty not just to sell products but to also create value for the consumers of their products. Value in the context of fresh produce could simply imply quality.

Horticultural produce, especially fruits and vegetables are still living even after harvest even though their source of nutrition has been cut off. For this reason, harvested fruits and vegetables undergo fast internal and external changes after harvest, depending on the commodity. In fact, a typical characteristic of most fresh FSC products is that the product quality declines as the product moves down the supply chain. For fresh fruits and vegetables, the rate of decline in quality depends on several postharvest factors (such as harvest season, packaging, storage, transportation, postharvest handling). The mentioned postharvest factors determine the amount of product to reach consumers in an optimum quality state [3, 31, 39]. According to [43], PHLs are partly a function of the available technology in a country as well as the extent to which markets for agricultural produce are developed. Hence no doubt why PHLs are high in FSCs of less developed countries as compared to developed countries where modern technologies abound.

Another fact is that most agricultural production sites are located in rural areas far from the urban cities where most target markets are located. The only choice becomes long transportation of harvested produce from production site to key markets. Literature shows that poor postharvest handling, transportation facilities, and bad road condition and network are amongst the ill factors affecting West-African agricultural production in general [50]. Transportation costs are very high with lots of unpredictable stops during transit; greatly increasing the problems of PHLs of perishable commodities [2, 10, 15, 24, 31, 49]. Since technology gaps, culture difference, and a number of other factors exist in differing fashion for different countries even states, FSCs can be unique to location. Therefore, a systematic analysis of the specific commodity supply chain is important for choosing appropriate and workable postharvest technologies [37].

A simplified illustration of the plantain FSC in Nigeria (Figure 1) was described by [7]. The study by [2] gave a clearer picture of the FSC by segmenting the value chain into three main sectors; upstream (input supplies and production), the midstream (assemblers or collectors, wholesalers, processors and exporters), the downstream (retailers and consumers). [2] also identified two levels of assemblers (farm-gate assemblers who gather produce from different farmers and market-arena assemblers who bring the produce to the wholesale market) and wholesalers (in-situ wholesalers sell in the market vicinity where they purchase and transit wholesalers who transport to other states and markets). Of the three sectors, the midstream sector was reported to be the dominant sector influencing price determination of plantain in almost all aspects of the chain [2].

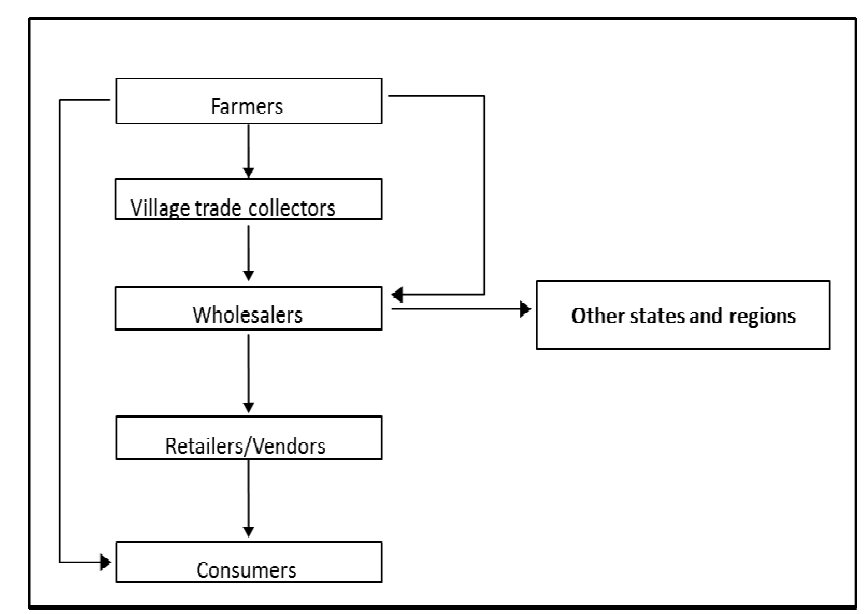

Source: [7]

Figure 1. Typical plantain supply chain in Nigeria

\section{Estimation of PHLs}

Estimating of PHLs is by either direct measurement (tracking) or indirect estimates via surveys interviews of producers and marketers who experienced the losses [30]. As expected, each approach has its advantages as well as shortcomings. While the direct measurement by tracking approach may focus only on discarded/quantitative losses, the estimate by survey approach may not give true representative values because of the possibility of underestimating or overestimating actual losses. The estimate by survey approach allows larger population samples whereas this is hardly possibly for direct measurement by tracking which is more tedious. Another approach of quantifying food losses is by mass flow of food flowing through the FSC. This approach was formulated by The Swedish Institute for Food and Biotechnology; and had been used by the FAO in [28] to study and quantify the causes and extent of food waste/losses using FAOSTAT regional data on production estimates. The mass flow method is only suitable in scenarios where production records and data are up to date. Currently, an up to date production database is a major problem in small scale farming systems of developing countries like Nigeria.

PHLs consist of qualitative and quantitative losses (Figure 2). Qualitative losses occur as a result of either altered physical condition, perceived substandard value, deterioration in texture, flavor and or nutritional value whereas quantitative losses refers to physical losses of food as unfit for human consumption and hence readily discarded $[35,30]$. Another aspect of postharvest loss is economic losses which apply when products of higher quality are restricted to lower markets. This type of loss would not be considered in the present study. All observed losses will be grouped either as quantitative or qualitative. 
While it is easier to measure quantitative PHLs, qualitative losses assessment is often difficult and complicated [35, 46]. According to [29], since changes in quality are determined by not just one factor but rather a number of factors included in an official grading standard, loss in quality may not be an actual loss of food. This further complicates assessment of qualitative losses and could be the reason why the African postharvest losses information system (APHLIS) which is a network model for grain loss assessment only measures quantitative losses and not qualitative.

Plantain is a staple in Nigeria and most of its PHLs are such that downgrades its quality and economic value making them undesirable for certain culinary uses and high-end markets. Therefore, assessments of both qualitative and quantitative losses in the plantain FSC are of equal importance.

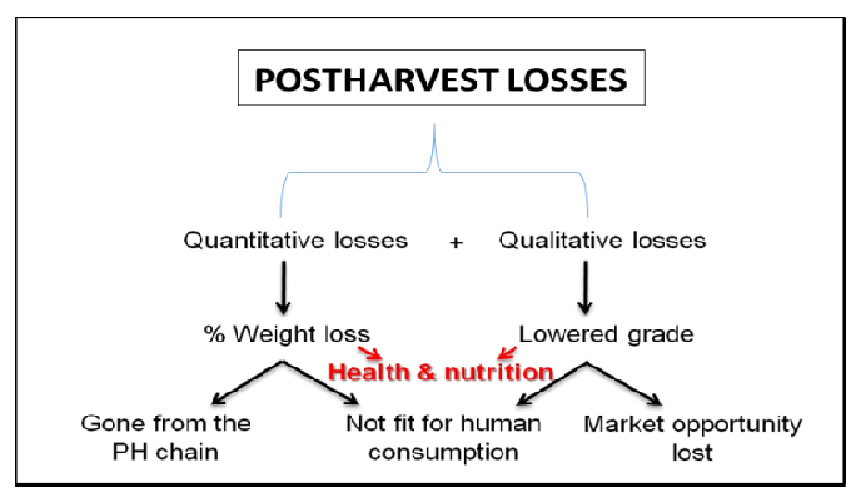

Source: Adapted from [29]

Figure 2. Description of postharvest losses

Generally, quantitative losses are measured by a number of methods such as weight of discarded, calorific value, lost inputs, greenhouse gas (GHG) emitted and cumulative weight loss [43]. If weighted values are obtained in each supply chain activity, the volume of PHLs can be estimated in terms of percentage losses with respect to total production volumes as described in the study by [45]. Alternatively, a "loss profile" described by APHLIS model could be obtained for plantain through collection of cumulative weight losses for each step of the supply chain with respect to the total production estimates [43, 44].

On the other hand, qualitative losses which is more of a subjective and abstract phenomenon is difficult to measure directly [35] and rather described in terms of perceived value or state of the product in question [8, 9, 50]. Though complicated, qualitative losses should not be ignored; because PHLs may not give a complete picture without qualitative losses. For this reason, measurement of qualitative postharvest losses should not be generalized but instead simplified to include only important valued factors for each commodity. For example, in the study by [50] quality of tomatoes fruits in the FSC were determined based on firmness being the most important perception of quality.

In defining quality of fresh fruits and vegetables, [46] identified two interesting orientations; product oriented quality and consumer oriented quality. Product orientation described quality objectively by a number of selected internal product attributes which are then used to measure the effects of treatments, handling techniques, storage conditions or other postharvest variables. In contrast, the consumer oriented defines quality in terms of consumer satisfaction of the product. Consumer satisfaction is critical for predicting market development and growth. It is not wrong to assume that consumer satisfaction would decrease as quality reduces and thereby provoke reduction in price value. Qualitative PHLs may therefore be indirectly measured as when a decline in quality causes a corresponding drop in economic/price value as in the study of fish postharvest losses by [42], and at the same time reduction in consumer satisfaction.

It should be noted that in reality, several factors (such as seasonal variations, product availability, target market, substitute products, value addition etc. could also cause a rise or drop in economic value/price for different reasons. Hence, over simplifying assessment of qualitative losses may cause biasness, this can be avoided by clearly noting the reasons for reduction in price value during data collection. Also, bias in estimating qualitative loss may be reduced by defining product quality from not just the product perspective but rather both product and consumer oriented perspectives of the fruit or vegetable in question [46]. In merging both perspectives of quality in a way that scores variables according to their order of importance with respect to the specific commodities a relationship could be established.

\section{Conceptual Framework}

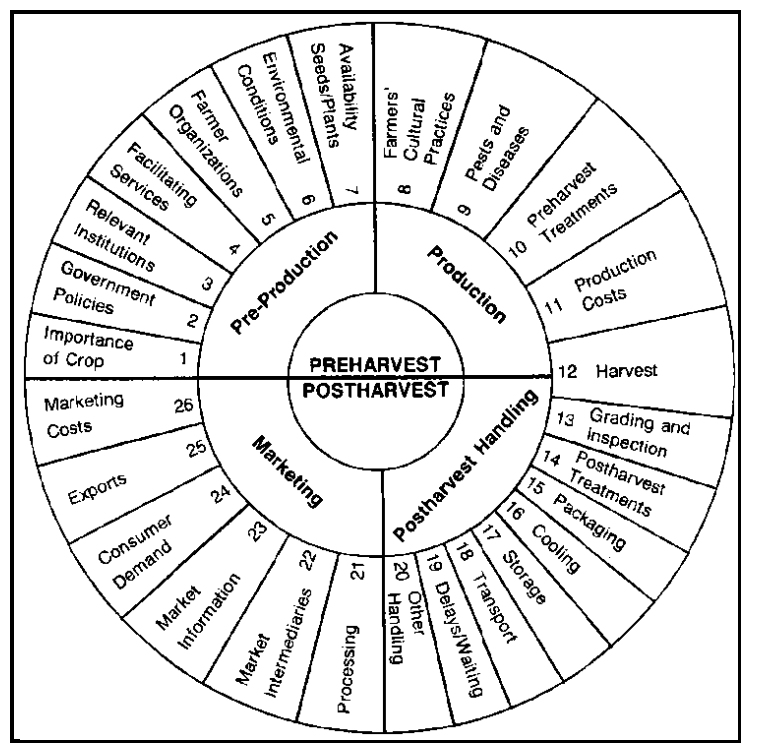

Source: [38]

Figure 3. Commodity system analysis

Commodity system analysis enables the identification of the different steps that occur from production to marketing of a product. A commodity system for an agricultural produce consists of about 26 components broadly grouped into preharvest and postharvest aspects [38] as seen in Figure 3. The 
postharvest aspect of the commodity system gives a general representation of the commodity's supply chain and can therefore be a useful approach to aid holistic assessment of PHLs. A systematic analysis of the production and postharvest handling of each commodity is the logical first step towards identifying sources of losses and appropriate postharvest solutions [35].

In this approach, the principle here is to de-categorize all activities in the postharvest system (postharvest handling and marketing) of the commodity in question into their tiniest bits and then directly measure their contribution to the overall losses observed. [11] described a similar framework for such assessment of postharvest losses in the supply chain.

A fact for typical agri-food supply chains is that fresh produce quantity and quality reduces as products travels down the supply chain $[17,46]$. Heavily deteriorated products end up being discarded as food waste while partially deteriorated produce may end up at reduced price values as earlier explained. The discarded produce and those provoking price reduction due to perceived reduced quality represents the quantitative and qualitative losses respectively. Both kinds of losses (qualitative and quantitative) when added gives the total amount of losses in the supply chain. This total loss is the PHLs for that particular supply chain and can be expressed as

$$
\begin{gathered}
\begin{array}{l}
\text { Total Postharvest losses }(\text { PHLs })=\left(\sum \text { Quantitative }+\sum\right. \\
\text { Qualitative) losses (see Figure } 2)
\end{array} \\
\% \text { PHLs }=(\text { Total production (tons) }- \text { PHLs (tons) }) \times 100
\end{gathered}
$$

It is noteworthy that every horticultural produce has a shelf life (postharvest life) following harvest. The shelf life of a product expires when the product is no longer useable and therefore discarded. Shelf life of fruits and vegetables partly depends on their quality at harvest, the postharvest handling offered and available market systems [27, 35]. In other words, the better the postharvest handling and marketing systems (Figure 3), the longer the shelf life. Nevertheless, the quality at harvest may influence the level of effectiveness of the postharvest handling and marketing towards shelf life. This is because agricultural produce could be manipulated to prolong its shelf life; however, its quality cannot be improved after harvest but only maintained $[12,20]$.

Discarded volume can be likened to quantitative PHLs which is measurable by the cumulative discarded losses in weight as produce moves along the supply chain. Furthermore, as fresh produce move down the supply chain, their perceived quality which is a function of extrinsic and intrinsic attributes $[8,9]$ such as fruit color, firmness, texture, freedom from defects $[8,9,16,26]$ also changes with respect to the postharvest handling and market systems in place. Perceived quality could therefore be used to indirectly estimate qualitative losses in plantain; making qualitative losses becomes a latent variable in this case.

A mathematical way to view this is quantitative losses applies when perceived quality reaches zero because product is unusable and therefore discarded. At this point shelf life also becomes zero as well. Qualitative losses on the other hand would be highest when quality is perceived to be optimum (likely the observed quality at harvest) and shelf life is maximum. As such it becomes very important to harvest agricultural produce at their optimum harvest time in order to obtain the best quality. From the above concepts, the following relationships can be developed as shown below in Figure 4.

Figure 4 illustrates a conceptual framework for directly estimating postharvest losses. It is assumed that shelf life is maximum at harvest and decreases as the product travels down the supply chain. From the framework, it is shown that three variables (quality at harvest, postharvest handling and market systems) independently contribute to the shelf life. The role of the quality at harvest, postharvest handing and market system towards shelf life are in turn determined by a number of various activities defined as factors A, B, and C for each respective variable. Decrease in shelf life translates into either qualitative or quantitative kinds of losses depending on the extent. Summation of both losses gives the total PHLs which increases as product travels down the supply chain.

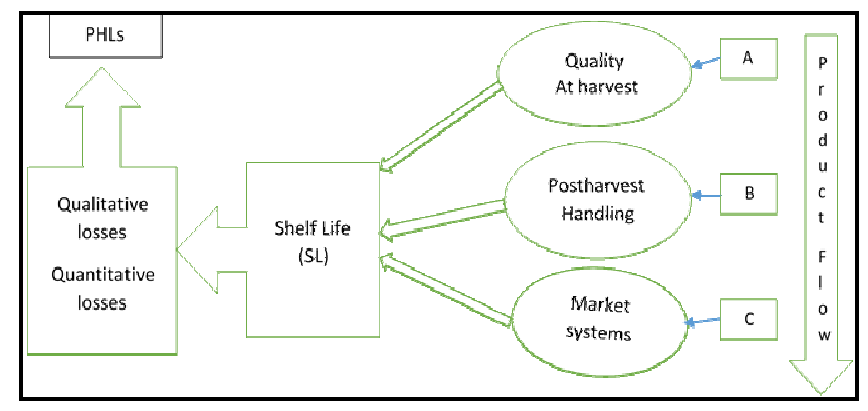

Figure 4. Conceptual framework for estimating PHLs

\section{Conclusion}

Review of literature highlights the necessity to reduce postharvest losses in agro-food supply chain. High PHLs in plantain which is a staple food in Nigeria with high economic development and export potential justifies its consideration for postharvest management studies. However, lack of information on exact causes of losses, and conflicting data on PHLs limits adaptation of workable technologies that are needed to curb losses in plantain and FSCs in general. The urgency and importance of comprehensive studies on loss assessment has necessitated the development of a hypothesized conceptual framework for direct estimation of PHLs. It is believed that application of this framework would enable unbiased documentation of exact losses and causative factors. This would be a stepping stone for mapping interventions and policies on PHLs solutions. s

\section{Acknowledgment}

The authors would like to thank the Organization for Women in Science for the Developing World (OWSD) for 
funding this research project.

\section{References}

[1] Adejoro, M.A., Odubanjo, A.O., \& Fagbola, B.O. (2010). Research Focus on Banana and Plantain (Musa spp.): Nigerian Perspectives. In T. Dubois et al., ed. Proc. IC on Banana \& Plantain in Africa. Acta Hort. 879, ISHS, 859-864.

[2] Adeoye, I.B., Oni, O.A., Yusuf, S.A., \& Adenegan, K.O. (2013). Plantain Value Chain Mapping in Southwestern Nigeria. Journal of Economics and Sustainable Development, 4(16), 137-146.

[3] Adewumi, M.O., Ayinde, O.E., Olatunji, G.B., \& Falana, O.I. (2009). Analysis of post harvest losses among plantain/banana (Musa Spp. L.) marketers in Lagos State, Nigeria. Nigerian Journal of Agriculture, Food and Environment, 5(2-4), 35-38.

[4] Ajayi, A.R. \& Aneke, M.O. (2002). Consumption and expenditure patterns of banana and plantain consumers in Nsukka, Urban, Nigeria. Info-Musa, 11, 50-53.

[5] Ajayi, A.R. \& Mbah, G.O. (2007). Identification of indegenious ripening technologies of banana and plantain fruits among women - marketers in southeastern nigeria. Agro-Science Journal, 6(2), 60-66.

[6] Akalumbe, Y.O.S., Ferris, D., Vuylsteke, R., Ortiz, \& Okunmadewa, F.Y. (1996). Socio-economic analysis of farm retail prices and post-harvest losses of plantain in southern Nigeria. Musa Research MUSAFRICA, 3, 12-13.

[7] Akinyemi, S. O. S., Aiyelaagbe, I. O. O., \& Akyeampong, E. (2010). Plantain (Musa spp.) Cultivation in Nigeria: a Review of Its Production, Marketing and Research in the Last Two Decades. Acta Horticulturae, 879, 211-218.

[8] Alonso, M.A.S., Gallego, P.A.M., \& Mangin, J.L. (2005). Testing a model of perceived food quality determinants. Journal of International Food and Agribusiness Marketing, 17(1), 9-33.

[9] Alonso, M.A.S., Paquin, J., \& Mangin, J.-P.L. (2002). Modelling perceived quality in fruit products: their extrinsic and intrinsic attributes. Journal of Food Products and Marketing, 8(1), 29-48.

[10] Atanda, S. A., Pessu, P. O., Agoda, S., Isong, I. U., \& Ikotun, I. (2011). The concepts and problems of post-harvest food losses in perishable crops. African Journal of Food Science, 5(11), 603-613.

[11] Aulakh, J., Regmi, A., Fulton, J., \& Alexander, C. (2013). Estimating Post-Harvest Food losses: Developing a Consistent Global Estimation Framework. In Agriculture \& Applied Economics Association's AAEA \& CAES Joint Annual Meeting. Washington, DC: Food and Agriculture Organization of the United Nations. Available at: http://webcache.googleusercontent.com/search?q=cache:wzgaH Gh66VAJ:www.fao.org/fileadmin/templates/ess/documents/mee tings_and_workshops/GS_SAC_2013/Improving_methods_for _estimating_post_harvest_losses/Final_PHLs_Estimation_6-1313.pdf $+\& \mathrm{~cd}=2 \& \overline{\mathrm{hl}}=\mathrm{en} \& \mathrm{ct}=\mathrm{clnk} \& \mathrm{gl}=\mathrm{my}^{-} \& \mathrm{client}=$ firefox-a.

[12] Bachmann, J., \& Earles, R. (2000). Postharvest handling of fruits and vegetables. ATTRA.

[13] Banks, N.H. (2009). Postharvest handling- A discipline that connects commercial, social, natural and scientific systems.
Florkowski, W. J., Prussia, S. E., Shewfelt, R. L., \& Brueckner, B. (Eds.), Postharvest handling: a systems approach. Academic Press.

[14] Baruwa, O.I., Masuku, M.B., \& Alimi, T. (2011). Economic analysis of plantain production in derived savannah zone of Osun State, Nigeria. Asian Journal of Agricultural Sciences, 3(5), 401-407.

[15] Bayeri, K.P. \& Nwachukwu, I. (2003). Storage methods influenced occurrence and severity of crown rot and anthracnose diseases on plantain (Musa spp. ABB) fruits during storage and post storage. p.201-204. In: A.S. Fasina, A.O. Olufolaji and V.C. Umeh (eds. In Proceeding of the 21st Annual Conference of the Horticultural Society of Nigeria. Lagos: Ess-Jay Business and Publishing Centre.

[16] Bramlage, W.J. \& Weis, S.A. (2004). Postharvest fruit quality and storage life in relation to mineral nutrients. New York Fruit Quarterly, 12(2), 11-12.

[17] Cai, X., Chen, J., Xiao, Y., Xu, X., \& Yu, G. (2013). Freshproduct supply chain management with logistics outsourcing. Omega, 41(4), 752-765.

[18] Cauthen, J., Jones, D., Gugert, M.K., \& Anderson, L. (2013). Banana and plantain value chain: West Africa EPAR, 239:25.

[19] CBN, 2003. Statistical Bulletins and Annual Report.

[20] Crisosto, C.H., Johnson, R.S., Day, K.R., \& DeJong, T. (1997) Orchard factors affecting postharvest stone fruit quality. HortScience, 32(5), 820-823.

[21] De Lucia, M., \& Assennato, D. (2006). Agricultural engineering in development: post-harvest operations and management of foodgrains. FAO Agricultural Services Bulletin (FAO).

[22] Dury, S., Bricas, N., Tchango-Tchango, J., Temple, L., \& Bikoi, A. (2002). The determinants of urban plantain consumption in Cameroon. Food quality and preference, 13(2), 81-88.

[23] Ebiowei, K.P. (2013). Empirical review of problems and prospects of banana (Musa Sapientum L) and plantain (Musa Paradisiaca L) production enterprises. Global Journal of Biology, Agricuture \& Health Sciences, 2(4), 181-186.

[24] Ekunwe, P.A. \& Ajayi, H.I. (2010). Economics of plantain production in Edo State Nigeria. Research Journal of Agriculture and Biological Sciences, 6(6), 902-905.

[25] FAOSTAT (2012). Plantain production statistics: Nigeria. Food and Agriculture Organisation of the United Nations Statistics Division. Available at: http://faostat3.fao.org/faostatgateway/go/to/download/Q/QC/E [Accessed August 14, 2014].

[26] Ferris, R.S.B., Ortiz, R.. \& Vuylsteke, D. (1999). Fruit quality evaluation of plantains, plantain hybrids, and cooking bananas. Postharvest Biology and Technology, 15, 73-81.

[27] Gorny, J.R. (2001). Post Harvest Management for Vegetables, Carlifornia. Available at: $\mathrm{http}: / /$ postharvest.ucdavis.edu/Produce/.

[28] Gustavsson, J., Cederberg, C., Sonesson, U., van Otterdijik, R., \& Meybeck, A. (2011). Global food losses and food waste: Extent, causes and prevention. Food and Agricultural Organization, 1-38. Available at: http://ucce.ucdavis.edu/files/datastore/234-1961.pdf [Accessed on September 29, 2014]. 
[29] Hodges, R.J., 2012. Postharvest Weight Losses of Cereal Grains in Sub-Saharan Africa. African postharvest Losses Information System. Available at: http://www.erails.net/FARA/aphlis/aphlis/weight-lossesreview/ [Accessed August 10, 2014].

[30] Hodges, R.J., Buzby, J.C., \& Bennett, B. (2010). Postharvest losses and waste in developed and less developed countries: opportunities to improve resource use. The Journal of Agricultural Science, 149(S1), 37-45.

[31] Idah, P.A., Ajisegiri, E.S.A., \& Yisa, M.G. (2007). Fruits and vegetables handling and transportation in Nigeria. AU Journal of Technology, 10(3), 175-183.

[32] IITA, 2011. Annual Report 2011, Oyo State, Nigeria.

[33] IITA, 2014. Banana \& Plantain. IITA Research to Nourish Africa, 1-3. Available at: http://www.iita.org/banana-andplantain [Accessed August 14, 2014].

[34] Kader, A.A. (2003). A perspective on postharvest horticulture (1978-2003 ). Horticultural Science, 38(5), 1004-1008.

[35] Kader, A.A. (2005). Increasing Food Availability by Reducing Postharvest Losses of Fresh Produce. In F. Mencarelli \& P. Tonutti, eds. 5th International Postharvest Symposium. Verona (Italy), 2169-2176.

[36] Kainga, P.E. \& Seiyabo, I.T. (2012). Economics of plantain production in Yenagoa Local Government Area of Bayelsa State. Journal of Agriculture and Social Research, 12(1), 114123.

[37] Kitinoja, L., Saran, S., Roy, S.K., \& Kader, A.A. (2011). Postharvest technology for developing countries: challenges and opportunities in research, outreach and advocacy. Journal of the Science of Food and Agriculture, 91(4), 597-603.

[38] LaGra, J. (1990). Appendix A: A postharvest loss assessment. In A commodity system assessment methodology for problem and project identification. Moscow, Idaho: Postharvest Institute for Perishables.

[39] Olayerni, F. F., Adegbola, J. A., Barnishaiye, E., \& Awagu, E. F. (2012). Assessment of Post Harvest Losses of Some Selected Crops in Eight Local Government Areas of Rivers State, Nigeria. Asian Journal of Rural Development, 2(1), 1323.

[40] Olayemi, F.F., Adegbola, J. A., Bamishaiye, E. I., \& Awagu, E. F. (2012). Assessment of Post Harvest Losses of Some Selected Crops in Eight Local Government Areas of Rivers State, Nigeria. Asian Journal of Rural Development, 2(1), 1323.
[41] Olorunda, A.O. \& Aworth, O.C. (1996). Overview of Musa research in postharvest technology at the department of food technology, University of Ibadan, Ibadan, Oyo State. In R. Qrtiz \& M. O. Akoroda, eds. In: Plantain and Banana Production and Research in West and Central Africa. Proceedings of a Regional Workshop (IITA), 75-76.

[42] Opara, L.U. \& Al-Jufaili, S.M. (2006). Quantification of fresh fish postharvest losses. Journal of Fisheries International, $1(2-4), 150-156$.

[43] Parfitt, J., Barthel, M., \& Macnaughton, S. (2010). Food waste within food supply chains: quantification and potential for change to 2050. Philosophical transactions of the Royal Society of London. Series B, Biological sciences, 365(1554), 3065-3081.

[44] Rembold, F., Hodges, R., Bernard, M., Knipschild, H., \& Léo, O. (2011). The African Postharvest Losses Information System (APHLIS). European Union, Luxembourg.

[45] Sharma, G. \& Singh, S.P. (2011). Economic analysis of postharvest losses in marketing of vegetables in Uttarakhand. Agricultural Economics Research Review, 24(December), 309-315.

[46] Shewfelt, R.L. (1999). What is quality? Postharvest Biology and Technology, 15(June), 197-200.

[47] Statista (2014). Global Banana Production. Available at: http://www.statista.com/statistics/264003/production-ofbananas-worldwide-by-region/ [Accessed July 25, 2014].

[48] Swennen, R., Vuylsteke, D., \& Ortiz, R. (1995). Phenotypic diversity and patterns of variation in West and Central African plantains (Musa spp., AAB group Musaceae). Economic botany, 49(3), 320-327.

[49] Tchango, J.T., Bikoï,A., Achard, R., Escalant, J.V. (1999). Banana (Plantain) Post-harvest Operations. Available at http://www.fao.org/fileadmin/user_upload/inpho/docs/Post_H arvest_Compendium - Plantain.pdf [Accessed September 30, 2014].

[50] Venus, V., Asare-Kyei, D.K., Tijskens, L.M.M., Weir, M.J.C; de Bie, C.A.J.M., Ouedraogo, S.,......Smaling, E.M.A. (2013). Development and validation of a model to estimate postharvest losses during transport of tomatoes in West Africa. Computers and Electronics in Agriculture, 92, 32-47. 